\title{
Effects of silymarin on p65 NF-kB, p38 MAPK and CYP450 in LPS-induced hoof dermal inflammatory cells of dairy cows
}

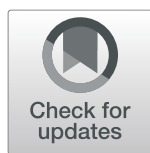

Meng-Yue Tian ${ }^{1+}$, Jing-Hui Fan ${ }^{1+}$, Zhi-Wei Zhuang ${ }^{2}$, Fei Dai ${ }^{1}$, Cheng-Yu Wang ${ }^{1}$, Hai-Ting Hou ${ }^{1}$ and Yu-Zhong Ma ${ }^{1 *}$ (D)

\begin{abstract}
Background: Laminitis is considered as one of the most important causes of hoof lameness in dairy cows, which can lead to enormous economic losses. However, the etiology and pathogenesis of laminitis have not been clarified yet. Besides, it is of great significant to find alternative herbs for the prevention and treatment of dairy hooves to avoid the antibiotic abuse. In this study, the primary hoof dermal cells of dairy cows were isolated, the inflammatory model was induced by LPS, and treated with silymarin to find whether silymarin has protective effect on the inflammatory dermal cells. The viability of dermal cells, the levels of IL-1 $\beta$ and TNF-a, the degree of p65 NF$\mathrm{KB}$ and P38 MAPK phosphorylation, the expressions of CYP3A4 and CYP1A1 were measured.

Results: Hoof dermal cells of dairy cows were successfully isolated and cultured by tissue adherent culture method. Certain concentrations of LPS can increase the levels of IL-1 $\beta$ and TNF- $a$, promote the phosphorylation of p65 NFKB and p38 MAPK, and inhibit the mRNA expressions of CYP3A4 and CYP1A1. The optimal concentration for LPS to establish a hoof dermal cells inflammatory model was $10 \mu \mathrm{g} / \mathrm{mL}$. Certain concentrations of silymarin can markedly decrease the secretions of IL-1 $\beta$ and TNF- $a$, inhibit the phosphorylation of p65 NF-KB and p38 MAPK, and promote the mRNA expressions of CYP3A4 and CYP1A1 in LPS-induced dermal inflammatory model.
\end{abstract}

Conclusions: LPS can be used for inducing the hoof dermal cells inflammatory model of dairy cows. Silymarin has protective effects on the LPS-induced inflammatory model.

Keywords: Silymarin, Dairy cow, Hoof dermal cell

\section{Background}

Hoof disease is one of the major diseases of dairy cows, among which laminitis is the most common one [1]. Laminitis is defined as a diffuse aseptic inflammation of corium in hoofed animals [2], which can lead to many kinds of claw horn lesions, including sole ulcers, white line disease and sole hemorrhage of dairy cows [3]. Economic losses caused by laminitis were enormous, which can severely restrict the development of dairy farming. In recent years, many scholars have focused on the pathophysiology [2], histology [4], metabolomics [5] and proteomics [6] of dairy cow laminitis, but the etiology and the pathogenesis have not been clarified yet.

\footnotetext{
* Correspondence: dkma@hebau.edu.cn

${ }^{\dagger}$ Meng-Yue Tian and Jing-Hui Fan contributed equally to this work.

${ }^{1}$ College of Veterinary Medicine, Hebei Agricultural University, 2596 Lekai

South Street, Baoding 071001, Hebei, China

Full list of author information is available at the end of the article
}

In previous studies, the acute laminitis model in vivo had been established successfully [7], whereas the interference caused by various physiological factors in vivo cannot be ignored, so there is still a high demand to establish an in vitro model for further exploration of laminitis.

Endotoxins, also known as lipopolysaccharides (LPS), is a major component of the outer membrane of Gram-negative bacteria. When the bacterial structure is destroyed, LPS will release into the blood and trigger a series of inflammatory reactions [8]. It showed that inflammatory reactions were the main pathological changes in early stages of laminitis [9]. Endotoxin is one of the key factors causing laminitis. For example, LPS concentrations increased in the serum of horses during oligofructose-induced laminitis model [10]. Intradermal injection of endotoxins into cattle induced a series of symptoms of laminitis [11]. Forelimbs exposed to LPS

(c) The Author(s). 2019 Open Access This article is distributed under the terms of the Creative Commons Attribution 4.0 International License (http://creativecommons.org/licenses/by/4.0/), which permits unrestricted use, distribution, and 
showed significant morphological changes in lamellar tissues and led to metabolic changes [12]. Therefore, stimulating the hoof dermal cells with LPS to establish an inflammatory model may be a novel way to explore the pathogenesis of laminitis.

Silymarin, a standardized extract of milk thistle, is a flavonoid, which is proved to have functions such as protecting liver [13], anti-oxidation [14], anti-inflammatory [15] and anti-cancer [16]. Clinical acute toxicity tests had demonstrated that silymarin generally had extremely low toxicity and no side effects on animal and human applications in certain dosage range [17]. In addition, previous studies have shown that silymarin could reduce endotoxin activities and improve the integrity of equine lamellar explants [18]. However, there is no scientific literature available to elucidate whether silymarin exhibits positive effects on bovine laminitis.

In this study, hoof dermal cells of dairy cows were isolated and cultured, the inflammatory model was established by LPS, and the inflammatory cells were treated with silymarin. The levels of IL-1 $\beta$ and TNF- $\alpha$, the phosphorylation of p65 NF- $\mathrm{kB}$ and $\mathrm{p} 38$ MAPK, and the expressions of CYP3A4 and CYP1A1 were determined to study whether silymarin had protective effects on the inflammatory dermal cells, and provide a theoretical basis for herbal medicine protection on laminitis of dairy cows.

\section{Methods}

\section{Materials}

LPS was purchased from Sigma (St. Louis, USA). Silymarin was purchased from Yihe Co. Ltd. (Xian, China). ELISA kits of bovine IL-1 $\beta$ and TNF- $\alpha$ were purchased from DG Biotech Co. Ltd. (Beijing, China). Antibodies against phosphor-p65 NF-кB, p65 NF-кB, phosphor-p38 MAPK, p38 MAPK and GADPH were purchased from Anyan trade Co. Ltd. (Shanghai, China). Total RNA extraction kit and reverse transcription kit were purchased from CW Biotech Co. Ltd. (Beijing, China). Fluorescence quantitative real time PCR kit was purchased from TransGen Biotech Co. Ltd. (Beijing, China). RT-PCR primers were synthetized by Sangon Biotech Co. Ltd. (Shanghai, China). RIPA cell lysis buffer, HE staining kit and BCA protein concentration determination kit were purchased from Solarbio (Beijing, China).

\section{Isolation and culture of hoof dermal cells}

Hoof tissues were obtained from adult healthy dairy cows at a commercial slaughter house. After shaved, cleansed and washed with $75 \%$ ethanol, the collected tissues were put into sterile saline solution with penicillin-streptomycin and transported on ice to the laboratory.
After rinsing with PBS and removing the subcutaneous connective tissues, the tissue blocks were trimmed into small pieces and incubated with $0.25 \%$ trypsin solution overnight at $4{ }^{\circ} \mathrm{C}$. Then, epidermis was separated and removed, and the dermis pieces were incubated in 6-well plates coated with rat tail collagen. DMEM medium supplemented with $15 \%$ fetal bovine serum (FBS), $0.025 \mathrm{M}$ HEPES, $1 \times$ Insulin-Transferrin-Selenium (ITS) and Gentamicin was used as cultivation medium. $500 \mu \mathrm{L}$ medium was pipetted carefully onto the tissue pieces to avoid flooding. $24 \mathrm{~h}$ later, when tissue pieces were attached to the plates, further $2 \mathrm{~mL}$ medium was added. Medium was changed every 3 days. Tissue pieces were removed 10 days later. Upon $80-90 \%$ confluency, the cells were detached with $0.25 \%$ trypsin-EDTA solution and seeded into $25 \mathrm{~cm}^{2}$ flasks.

For morphological staining, the cells were seeded on cover glass and stained by the HE staining kit, according to the manufacturer's instructions.

\section{Cell viability}

Hoof dermal cells were seeded into 96-well plates with a density of $1 \times 10^{5}$ cells per well. After incubation with gradient concentrations of LPS or silymarin for $48 \mathrm{~h}$, $20 \mu \mathrm{L} 5 \mathrm{mg} / \mathrm{mL}$ MTT was added per well. $4 \mathrm{~h}$ later, $100 \mu \mathrm{L}$ DMSO was added. After vibrated for $5 \mathrm{~min}$, the absorbance value was measured by microplate reader.

\section{Treatment of the LPS-induced inflammatory cells with Silymarin}

The silymarin-DMSO solution was diluted with DMEM medium and filtered with $0.22 \mu \mathrm{m}$ microfilter. The LPS-induced inflammatory hoof dermal cells were treated with gradient concentrations of silymarin for 24 $\mathrm{h}$ and $48 \mathrm{~h}$, respectively.

\section{ELISA measurement of IL- $1 \beta$ and TNF- $\alpha$}

The contents of IL-1 $\beta$ and TNF- $\alpha$ in cell supernatants of the control group, the LPS treated groups, and the silymarin treated groups were detected by ELISA kit, respectively, according to manufacturer's instructions.

\section{Western blot analysis of p65 NF-KB and p38 MAPK phosphorylation}

The total proteins were obtained by RIPA cell lysis buffer, quantified by BCA protein concentration determination kit, and then denatured, run in $12 \%$ SDS-polyacrylamide gel and electrotransferred to nitrocellulose membranes. The membranes were blocked with $5 \%$ non-fat milk for $1 \mathrm{~h}$ at room temperature, incubated with antibodies against p65 NF- $\mathrm{B}$, phosphor-p65 NF- $\mathrm{BB}$, p38 MAPK, phosphor-p38 MAPK or GADPH at $4{ }^{\circ} \mathrm{C}$ overnight. After three times washing with TBST, the membranes were incubated with horse-radish peroxidase (HRP)-conjugated anti-rabbit IgG 
$(\mathrm{H}+\mathrm{L})$ secondary antibody (1:2000 in TBST) for $1 \mathrm{~h}$ at room temperature. After a final series of washing, the membranes were placed into NBT/BCIP chromogen kit for development. Relative intensity of each protein band/sample was quantified using Image J software.

\section{CYP3A4 and CYP1A1 mRNA expressions by RT-PCR analysis}

Total cellular RNA was obtained using RNA extraction kit. After evaluated by NanoDrop 2000 spectrophotometer, the total RNA was purified and reversed into cDNA using reverse transcription kit, according to the manufacturer's instructions. The resulting cDNA was used to detect the relative expression levels of CYP3A4 and CYP1A1 by fluorescence quantitative real time PCR. Primers used for amplification were: CYP3A4, 5' - GGAAACCTGGGTTCTCCTG GCT- 3' (forward), and 5'-CCGATGGACCAAAAACCCT CCG- 3' (reverse); CYP1A1， 5'-GACCTGAATCAGAG GTTCTACGTCT- 3' (forward), and 5'-CCGGATGTG ACCCTTCTCAA- 3' (reverse); GADPH, 5'-ATGGAGAA GGCTGGGGCTCACT-3' (forward), and 5' -AGTCCCTCC ACGATGCCAAAGT-3' (reverse). The reaction volumes were $20 \mu \mathrm{L}\left(2 \times\right.$ TransStart $^{\circ}$ Top Green qPCR SuperMix $10 \mu \mathrm{L}, 10 \mu \mathrm{M}$ forward primer $0.4 \mu \mathrm{L}, 10 \mu \mathrm{M}$ reverse primer $0.4 \mu \mathrm{L}$, template $1 \mu \mathrm{L}$, water $8.2 \mu \mathrm{L}$ ). PCR was performed as follows: template denaturation at $95{ }^{\circ} \mathrm{C}$ for $5 \mathrm{~min}$, and 30 cycles of denaturation at $95^{\circ} \mathrm{C}$ for $30 \mathrm{~s}$, primer annealing at $\mathrm{Tm}-3{ }^{\circ} \mathrm{C}$ for $30 \mathrm{~s}$, and primer extension at $72^{\circ} \mathrm{C}$ for $30 \mathrm{~s}$, followed by a final extension at $72{ }^{\circ} \mathrm{C}$ for $5 \mathrm{~min}$. The relative expression level for each gene was calculated using the $2^{-\Delta \Delta \mathrm{Ct}}$ method and GADPH was used as an reference gene.

\section{Statistical analysis}

Data were presented as mean \pm SD of at least three separate experiments. Significant differences among groups were determined by one-way analysis of variance (ANOVA) with Duncan's post hoc test using SPSS 19.0 software (SPSS, Inc., Chicago, IL). A two-tailed $P$-value below 0.05 was considered as statistically significant.

\section{Results}

\section{Configuration of bovine hoof dermal cells}

The primary bovine hoof dermal cells isolated from tissue blocks cultured slowly. Observed under inverted microscope, dermal cells began to climb out from the edge of tissue blocks after 5-7 days of inoculation (Fig. 1a). The adherent cells approached confluence and could be sub-cultivated after incubation for 15-20 days (Fig. 1b). For HE staining, the sub-cultured cells grew well and could be used for the following experiment (Fig. 1c, d).
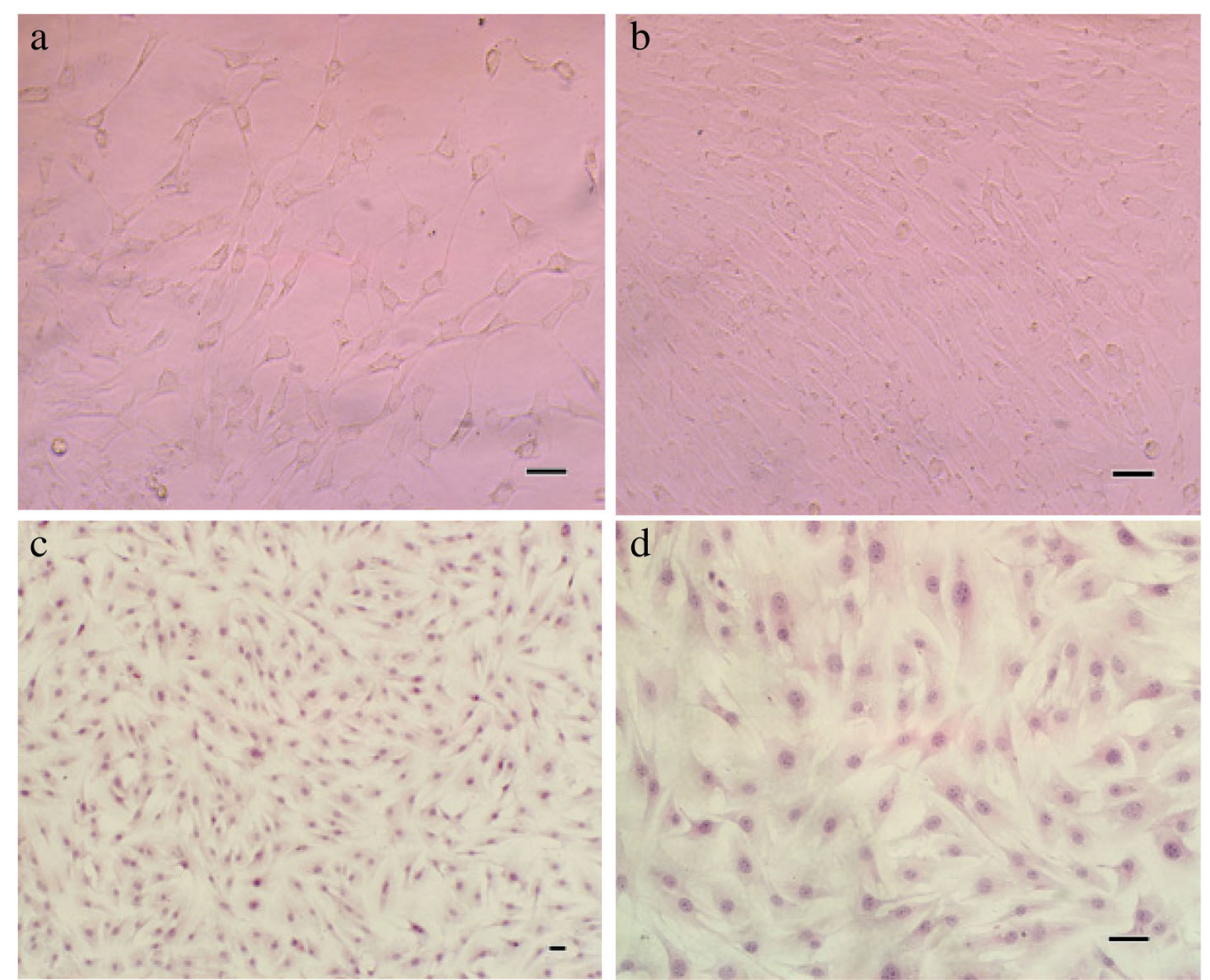

Fig. 1 Representative photographs of bovine hoof dermal cells morphological analysis. a. After seeding of the tissue blocks, cells started to proliferate, showing an irregular triangle or fusiform shape; b. After inoculation for 15 days, dermal cells were mostly fusiform, with a certain flow direction; c, d. The sub-cultured dermal cells after HE staining were irregular in shape, polygonal or long fusiform. (scale $=100 \mu \mathrm{m})$ 
Table 1 The inhibitory effect of LPS on dermal cells $(n=8)$

\begin{tabular}{lll}
\hline LPS $(\mu \mathrm{g} / \mathrm{mL})$ & Absorbance value & $\mathrm{IR}(\%)$ \\
\hline 0 & $0.865 \pm 0.074$ & 0 \\
1 & $0.842 \pm 0.050$ & 2.61 \\
5 & $0.803 \pm 0.052$ & 7.10 \\
10 & $0.772 \pm 0.050^{*}$ & 10.73 \\
20 & $0.702 \pm 0.025^{* *}$ & 18.80 \\
50 & $0.622 \pm 0.036^{* *}$ & 28.08
\end{tabular}

Note: Cells were treated with gradient concentrations of LPS for $48 \mathrm{~h}$, and the viability was monitored by MTT assay. Value indicated are the mean \pm SD ( ${ }^{* *} P$-value $<0.01 ;{ }^{*} P$-value< 0.05$)$. The inhibition ratio $(I R)=1-($ the test group OD value/ the control group OD value)

\section{Selection of the optimal concentration of LPS for the inflammatory model}

The inhibition ratio (IR) increased with the gradient concentrations of LPS treatment, $10 \mu \mathrm{g} / \mathrm{mL}$ group was the nearest to $10 \%$ (Table 1). The phosphorylation of p65 NF-kB and p38 MAPK increased with the treatment of LPS for $48 \mathrm{~h}$. For the expressions of p-p65 NF-kB, 10, $20,50 \mu \mathrm{g} / \mathrm{mL}$ LPS groups were significantly different with that in the control group $(P<0.05)$, and the expressions of p-p38 MAPK increased significantly with the treatment of the $5,10,20,50 \mu \mathrm{g} / \mathrm{mL}$ LPS $(P<0.05)$ (Fig. 2a). The IL-1 $\beta$ secretions increased first and then decreased with the gradient concentrations of LPS treatment, reaching a peak at $10 \mu \mathrm{g} / \mathrm{mL}$, which was extremely significantly different with that in the control group $(P<0.01)$ (Fig. 3a). After treatment with $10 \mu \mathrm{g} / \mathrm{mL}$ LPS for $24 \mathrm{~h}$ and $48 \mathrm{~h}$, the secretion of TNF- $\alpha$ was significantly different with that in the control group $(P<0.05)$ (Fig. 3b). The expressions of CYP3A4 significantly decreased with the treatment of $1,5,10 \mu \mathrm{g} / \mathrm{mL}$ LPS for $24 \mathrm{~h}$, and $1,5,10,20,50 \mu \mathrm{g} / \mathrm{mL}$ LPS for $48 \mathrm{~h}(P<0.05)$ (Fig. 4a). The expressions of CYP3A4 extremely significantly decreased with the treatment of $1,5,10,50 \mu \mathrm{g} / \mathrm{mL}$ LPS for $24 \mathrm{~h}$, and $1,5,50 \mu \mathrm{g} / \mathrm{mL}$ LPS for $48 \mathrm{~h}(P<0.01)$ (Fig. $4 \mathrm{~b})$. From the above, $10 \mu \mathrm{g} / \mathrm{mL}$ LPS was the optimal concentration for inducing the inflammatory model of hoof dermal cells.

\section{Expressions of p65 NF-kB, p38 MAPK and CYP450 with gradient silymarin treatment}

Independent of the concentration, silymarin had no influence on the viability of hoof dermal cells (Table 2). Compared with the LPS model group, the phosphorylation of p65

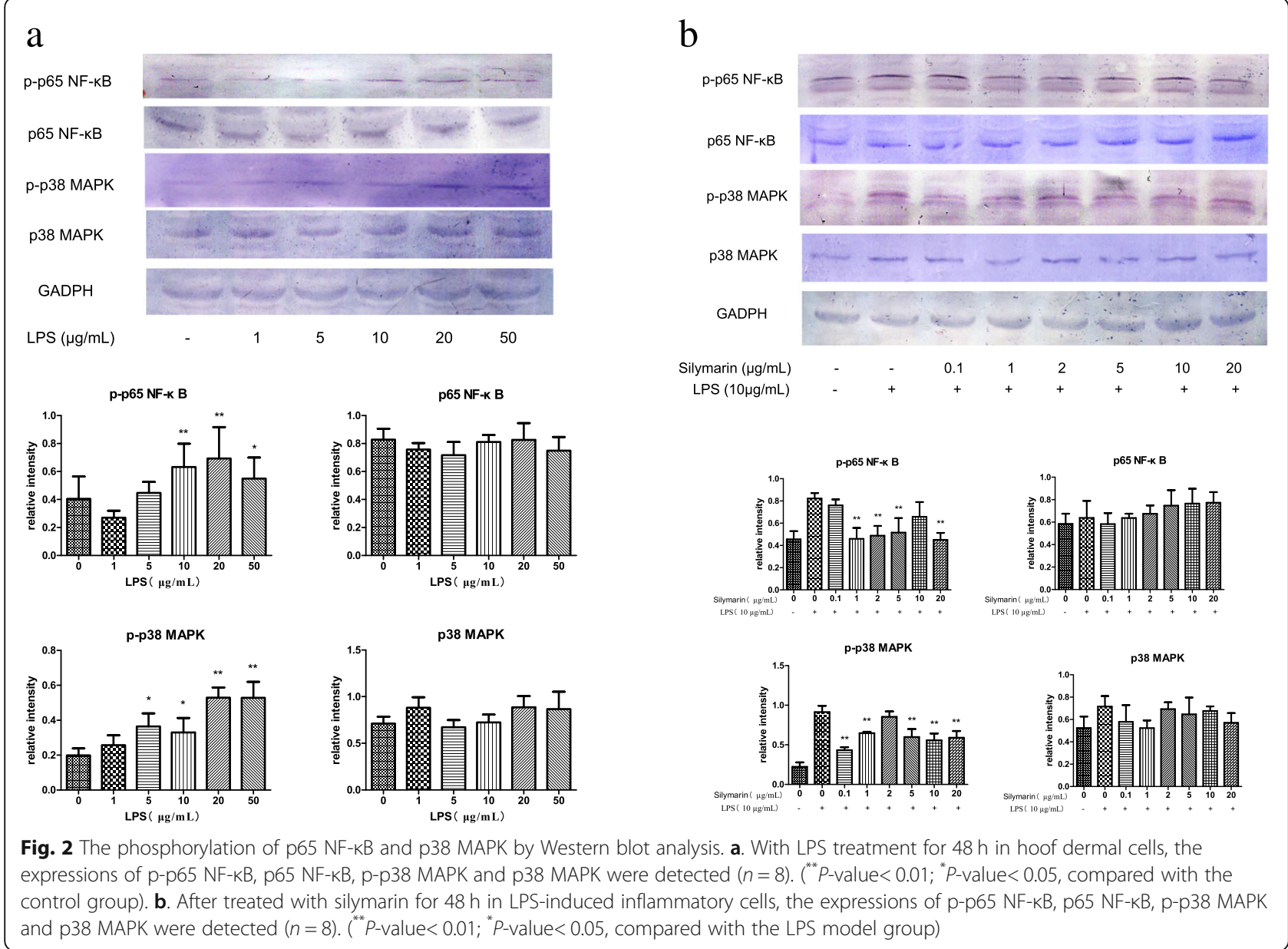



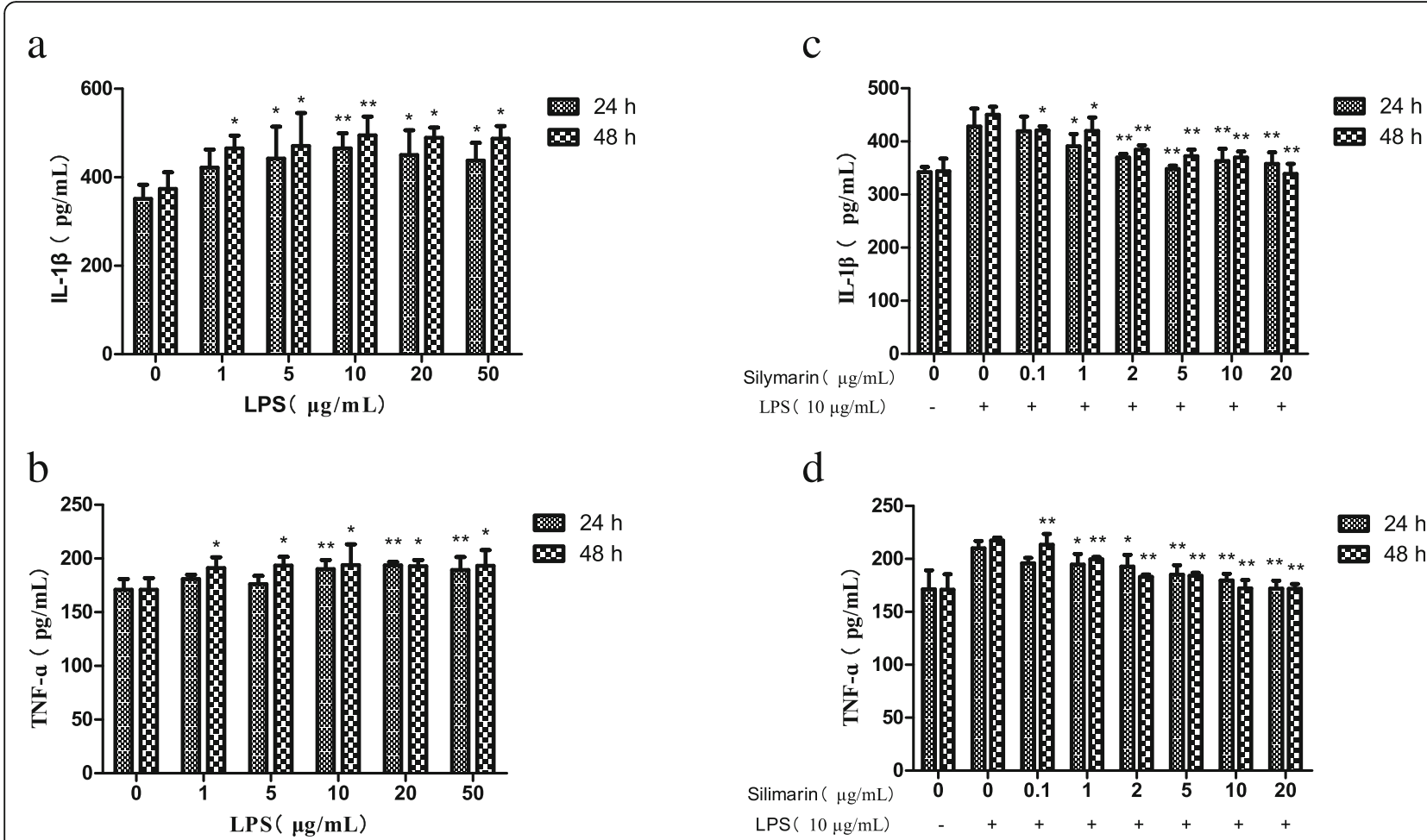

Fig. 3 The levels of IL-1 $\beta$ and TNF-a measured by ELISA. After treated with gradient concentrations of LPS in hoof dermal cells for $24 \mathrm{~h}$ and $48 \mathrm{~h}$, levels of IL-1 $\beta(\mathbf{a})$ and TNF-a $(\mathbf{b})$ were detected $(n=8)$. ( ${ }^{* *} P$-value $<0.01 ;{ }^{*} P$-value $<0.05$, compared with the control group). After treated with gradient concentrations of silymarin in LPS-induced hoof dermal inflammatory cells for $24 \mathrm{~h}$ and $48 \mathrm{~h}$, levels of IL-1 $\mathrm{B}$ (c) and TNF-a (d) were detected $(n=8)$. ( ${ }^{* *} P$-value $<0.01 ;{ }^{*} P$-value $<0.05$, compared with the LPS model group)

NF- $\mathrm{kB}$ and $\mathrm{p} 38$ MAPK decreased with the treatment of silymarin for $48 \mathrm{~h}$. The inhibition effects of p65 NF-kB phosphorylation were extremely significant in the $1,2,5$ and $20 \mu \mathrm{g} / \mathrm{mL}$ groups $(P<0.01)$ (Fig. 2b). The phosphorylation of p38 MAPK decreased extremely significant with the $0.1,1,5$, 10, $20 \mu \mathrm{g} / \mathrm{mL}$ silymarin treatment $(P<0.01)$ (Fig. 2b). With the gradient concentrations of silymarin treatment, the secretions of IL- $1 \beta$ and TNF- $\alpha$ decreased compared with the LPS model group. There were significant differences between silymarin groups and the model group $(P<0.05)$ except the $0.1 \mu \mathrm{g} / \mathrm{mL}$ treatment for $24 \mathrm{~h} \quad(P>0.05)$ (Fig. 3c, d). Regardless of concentrations, the expressions of CYP3A4 increased significantly with the silymarin treatment for $24 \mathrm{~h}$ and $48 \mathrm{~h}$, compared with the LPS model group. $(P<0.05)$ (Fig. $4 \mathrm{c})$. The expressions of CYP1A1 significantly increased with the treatment of $0.1,1,5,20 \mu \mathrm{g} / \mathrm{mL}$ silymarin for $24 \mathrm{~h}$, and $1,5 \mu \mathrm{g} / \mathrm{mL}$ silymarin for $48 \mathrm{~h}(P<0.05)$ (Fig. $4 \mathrm{~d})$. Above all, silymarin had protective effects on the LPS-induced hoof dermal cells inflammatory model, and $1 \mu \mathrm{g} / \mathrm{mL}$ silymarin was the optimal concentration.

\section{Discussion}

Laminitis is the major cause of lameness in dairy cows, leading to serious economic loss. However, the etiology and pathogenesis of laminitis have not been clarified yet. Establishment of an in vitro model may be a novel way to solve the problem.

The common way for dermal cells isolation and culture is enzymatic digestion, which is frequently used in young animals such as embryonic rats [19] and fetal calves [20]. However, after digested with $1 \mathrm{~g} /$ $\mathrm{L}$ and $2 \mathrm{~g} / \mathrm{L}$ type I collagenase in $37^{\circ} \mathrm{C}$ for $2-4 \mathrm{~h}$, no viable dermal cells were obtained. Various factors might be responsible for the failure, such as the type of enzyme, concentration of enzyme and digestion time. Therefore, further researches are needed to figure out whether hoof dermal cells of dairy cows could be isolated by enzymatic digestion. Tissue blocks for dermal cells culture are usually taken from the skins behind ears [21] and shoulders [22]. Hendry established a short-term culture method for bovine hoof explants, but did not obtain the dermal cells [23]. Based on the previous studies, the tissue blocks were firstly incubated in $0.25 \%$ trypsin solution, separated from the epidermis, and then cultured in plates in this experiment. Although dermal cells grew slowly by this method, the operation was simple and convenient, and the damage of the enzyme was alleviated, the interaction between cells could be preserved well. 
a

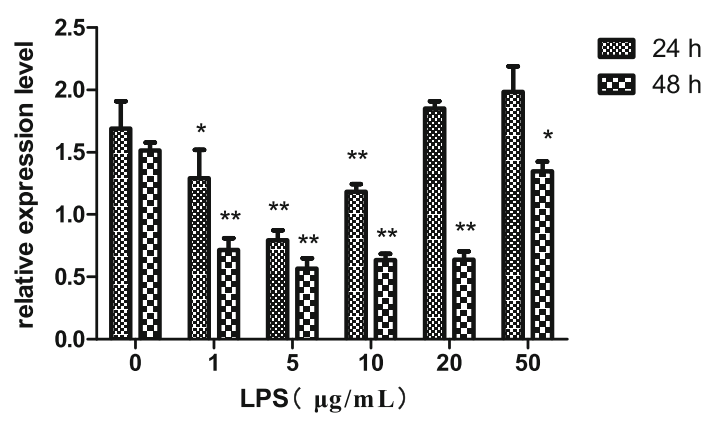

$\mathrm{C}$

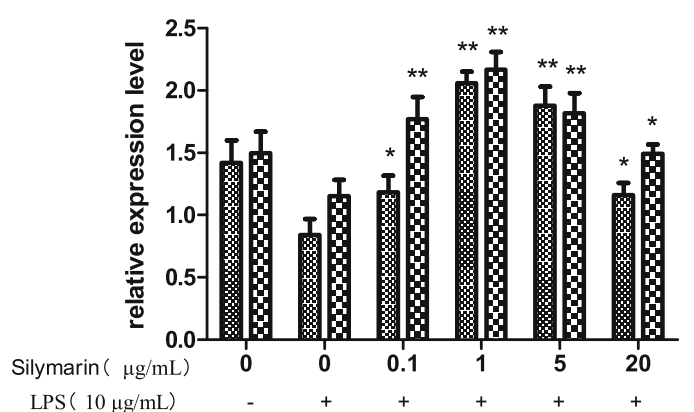

$\mathrm{b}$

CYP1A1

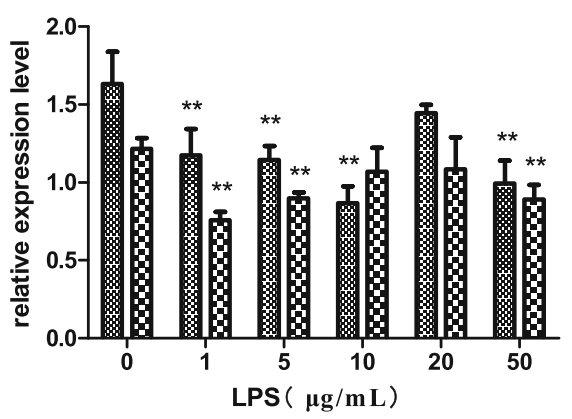

d

CYP1A1

$24 \mathrm{~h}$

ED $48 \mathrm{~h}$

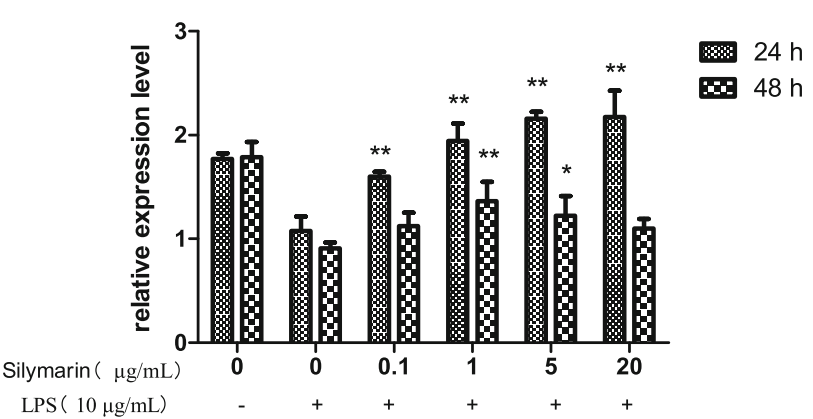

Fig. 4 CYP3A4 and CYP1A1 expressions measured with qRT-PCR. With LPS treatment for $24 \mathrm{~h}$ and $48 \mathrm{~h}$ in hoof dermal cells, the expressions of CYP3A4 (a) and CYP1A1 (b) were detected $(n=8) .\left(^{* *} P\right.$-value $<0.01 ;{ }^{*} P$-value $<0.05$, compared with the control group). After treated with silymarin for $24 \mathrm{~h}$ and $48 \mathrm{~h}$ in LPS-induced inflammatory cells, the expressions of CYP3A4 (c) and CYP1A1 (d) were detected $(n=8) .\left({ }^{* *} P\right.$-value $<0.01 ;{ }^{*} P$-value $<0.05$, compared with the LPS model group)

Once entering the body, LPS will firstly bind with LBP and CD14 to form a ternary complex, which can be recognized by TLR4. Then the complex will activate MyD88dependent pathway and MyD88-independent pathway, initiate intracellular signaling, activate NF- $\mathrm{kB}$ and MAPK signaling pathways, and finally trigger a series of pathophysiological reactions [24]. Nuclear factor- $\mathrm{kB}$ (NF-kB), also known as nuclear transcription factor, is the junction of multiple signal transduction pathways, heterodimer p50-p65 is its common form [25]. When activated by external stimulations like LPS, NF-kB will be released from the NF-кB-ІкB $\alpha$ complex, transferred into nucleus, to initiate transcription of downstream genes [26]. Besides,

Table 2 The toxic effects of Silymarin on dermal cells $(n=8)$

\begin{tabular}{ll}
\hline Silymarin $(\mu \mathrm{g} / \mathrm{mL})$ & Absorbance value \\
\hline 0 & $0.841 \pm 0.033$ \\
1 & $0.842 \pm 0.040$ \\
5 & $0.841 \pm 0.036$ \\
10 & $0.839 \pm 0.037$ \\
20 & $0.843 \pm 0.045$ \\
\hline
\end{tabular}

Note: Cells were treated with gradient concentrations of silymarin for $48 \mathrm{~h}$, and the viability was monitored by MTT assay. Absorbance value was expressed as mean \pm SD mitogen-activated protein kinase (MAPK) is also an important signaling pathway of cells. Its subfamily p38 MAPK has the closest relationship with the inflammatory response induced by LPS [27]. NF-kB and MAPK signaling pathways play a key role in the immune response, inflammatory response, stress response, cell proliferation and apoptosis, etc. [28, 29]. In some studies it showed that there was a time-dependent increase in platelet p38 MAPK phosphorylation in the horse laminitis model induced by oligofructose, demonstrating that LPS activates platelets, leading to activation of leukocytes, and initiates the early inflammatory changes of acute laminitis [11]. In this experiment, the phosphorylation of p65 NF- $\kappa B$ and p38 MAPK increased after LPS treatment, which was consistent with previous studies. The secretions of IL- $1 \beta$ and TNF- $\alpha$ increased with the gradient concentrations of LPS treatment, reaching a peak at $10 \mu \mathrm{g} / \mathrm{mL}$, which was significantly different from the control group. It have shown that in equine laminitis models induced by carbohydrate [30] and black walnut overload [31], the levels of inflammatory factors such as TNF- $\alpha$, IL- $1 \beta$ and IL- 6 increased, indicating that cytokines play an important role in the 
pathological development of laminitis. Cytochrome P450 (CYP450), also known as mono-oxygenase, drug-metabolizing enzyme, and multifunctional oxidase, is an important metabolic enzyme and involves in the metabolism of many endogenous and exogenous compounds [32]. Its three major subfamilies, CYP1, CYP2 and CYP3, play an important role in the metabolism and detoxification process [33]. The inflammation down-regulated the expressions of different subfamilies of CYP450 enzymes, leading to alterations in the pharmacokinetics of xenobiotics [34,35]. Multiple studies have shown a rapid down-regulation of hepatic CYPs following administration of LPS [36, 37]. By RT-PCR method, our results proved that the expressions of CYP3A4 and CYP1A1 obviously decreased with the treatment of 1 , 5, $10 \mu \mathrm{g} / \mathrm{mL}$ LPS. All above results demonstrated that the LPS-induced hoof dermal cells inflammatory model was established successfully.

At present, antibiotic injection is the main way for laminitis treatment [38]. However, with the abuse of antibiotics, the problems of drug resistance and side effects get worse. It is of great significance to find alternative herbs for the prevention and treatment of dairy hooves. Silymarin, which is an extract isolated from the fruit, rhizome and seeds of milk thistle, was proved to be a potent anti-inflammatory agent in the present study [15]. MTT assay was used to detect the toxic effects of silymarin, and the result showed that silymarin had no statistically significant effect on the viability of hoof dermal cells within the time and concentrations range determined in this experiment. In cigarette smoke-induced airway inflammatory model [39], bleomycin-induced pulmonary toxic model [40], and CCl4-induced liver damage model of mice [41], silymarin effectively inhibits the expressions of inflammatory cytokines such as TNF- $\alpha$, IL-1 $\beta$, IL- 6 and IL-8. In the present study, it is further confirmed that the treatment with silymarin could decrease the levels of cytokines. Our data, and those of others, have demonstrated that the anti-inflammatory effect of silymarin might act through the NF- $\mathrm{KB}$ and MAPK signaling pathways $[39,42]$. The expressions of CYP450s can be modulated by cytokines during inflammation, resulting in changes to the pharmacokinetics of medications. Therefore, CYP450 can be used for the development of new anti-inflammatory drugs and contribute to variability in drug efficacy or toxicity in inflammatory disease [43]. The present study showed that silymarin increased the expressions of CYP3A4 and CYP1A1, which indicated its effectiveness and securities as a potent anti-inflammatory agent. To sum up, silymarin plays an important role in protecting the LPS-induced inflammatory model of hoof dermal cells.

\section{Conclusions}

$10 \mu \mathrm{g} / \mathrm{mL}$ LPS can be used for inducing hoof dermal cells inflammatory model of dairy cows. $1 \mu \mathrm{g} / \mathrm{mL}$ silymarin can alleviate the inflammatory responses of hoof dermal cells caused by LPS stimulation in dairy cows. This study established a new experimental model for the study of laminitis in vitro, and can provide some useful information for the herbal medicine protection from animal hooves diseases.

\section{Abbreviations \\ CYP450: Cytochrome P450; DMEM: Dulbecco's Modified Eagle Medium; DMSO: Dimethyl sulphoxide; EDTA: Ethylenediaminetetraacetic acid; ELISA: Enzyme-linked immunosorbent assay; FBS: Fetal bovine serum; HE staining: hematoxylin-eosin staining; IL-1 $\beta$ : Interleukin-1 $\beta$; IR: inhibition ratio; ITS: Insulin-Transferrin-Selenium; LPS: lipopolysaccharides; MAPK: mitogen- activated protein kinase; MTT: Methylthiazolyldiphenyl-tetrazolium; NF- kB: Nuclear factor-kB; PBS: Phosphate buffered saline; TNF-a: Tumor necrosis factor-a}

\section{Acknowledgements}

Not applicable.

\section{Funding}

This work was supported by the Hebei Dairy Cattle Innovation Team of Modern Agro-industry Technology Research System (HBCT2018120406), and the Hebei Beef Innovation Team of Modern Agro-industry Technology Research System (HBCT20181130405). The funding agencies did not participate in study design, data collection, analysis and interpretation or writing of the manuscript.

\section{Availability of data and materials}

The datasets used and analysed during the current study are available from the corresponding author on reasonable request.

\section{Authors' contributions \\ YZM conceived and designed the study, and critically revised the manuscript. MYT and JHF performed most of the experiments and analyzed the results, and MYT drafted the manuscript. ZWZ assisted in experimental design, data interpretation and manuscript preparation. FD contributed to samples collection, cell culture and manuscript revision. CYW performed QPCR experiment and helped with the data analysis. HTH participated in ELISA and western blot experiments. All authors read and approved the final manuscript.}

\section{Ethics approval and consent to participate}

Hoof tissues were obtained from adult healthy dairy cows at Baoding Lianchi slaughter house (Hebei, China) and were used with the consent of the slaughter house. All dairy cows were slaughtered for meat production and no animal was slaughtered specifically for the purpose of tissue collection.

\section{Consent for publication}

Not applicable.

Competing interests

The authors declare that they have no competing interests.

\section{Publisher's Note}

Springer Nature remains neutral with regard to jurisdictional claims in published maps and institutional affiliations.

\section{Author details}

${ }^{1}$ College of Veterinary Medicine, Hebei Agricultural University, 2596 Lekai South Street, Baoding 071001, Hebei, China. ${ }^{2}$ Shandong New Hope Liuhe Co. Ltd, Qingdao 266000, Shandong, China. 


\section{Received: 25 November 2018 Accepted: 12 April 2019} Published online: 30 April 2019

\section{References}

1. Waaij $E, H$, Holzhauer M, Ellen E, Kamphuis C, Jong G. Genetic parameters for claw disorders in Dutch dairy cattle and correlations with conformation traits. J Dairy Sci 2005, 88(10):3672-3678.

2. Boosman R, Nemeth F, Gruys E. Bovine laminitis: clinical aspects, pathology and pathogenesis with reference to acute equine laminitis. Vet Q. 1991; 13(3):163-71.

3. Vermunt JJ. One step closer to unravelling the pathophysiology of claw horn disruption: for the sake of the cows' welfare. Vet J. 2007;174(2):219-20.

4. Danscher AM, Toelboell TH, Wattle O. Biomechanics and histology of bovine claw suspensory tissue in early acute laminitis. J Dairy Sci. 2010;93(1): 53-62.

5. Momcilovic D, Herbein JH, Whittier WD, Polan CE. Metabolic alterations associated with an attempt to induce laminitis in dairy calves. J Dairy Sci. 2000;83(3):518-25.

6. Dong SW, Zhang SD, Wang DS, Wang H, Shang XF, Yan P, Yan ZT, Yang ZQ. Comparative proteomics analysis provide novel insight into laminitis in Chinese Holstein cows. BMC Vet Res. 2015;11(1):161.

7. Thoefner MB, Pollitt CC, Eps AW, Milinovich GJ, Trott DJ, Wattle O, Andersen $\mathrm{PH}$. Acute bovine laminitis: a new induction model using alimentary oligofructose overload. J Dairy Sci. 2004;87(9):2932-40.

8. Lepper PM, Held TK, Schneider EM, Bölke E, Gerlach H, Trautmann M. Clinical implications of antibiotic-induced endotoxin release in septic shock. Intensive Care Med. 2002;28(7):824-33.

9. Belknap JK. Black walnut extract: an inflammatory model. Vet Clin North Am Equine Pract. 2010;26(1):95-101.

10. Bailey SR, Adair HS, Reinemeyer CR, Morgan SJ, Brooks AC, Longhofer SL Elliott J. Plasma concentrations of endotoxin and platelet activation in the developmental stage of oligofructose-induced laminitis. Vet Immunol Immunopathol. 2009;129(3):167-73.

11. Boosman R, Mutsaers CW, Klarenbeek A. The role of endotoxin in the pathogenesis of acute bovine laminitis. Vet Q. 1991;13(3):155-62.

12. Patan-Zugaj B, Gauff FC, Licka TF. Effects of the addition of endotoxin during perfusion of isolated forelimbs of equine cadavers. Am J Vet Res. 2012;73(9):1462.

13. Jann-Inn T, Mei-Fen C, Hsien-Hui C, Juei-Tang C. Silymarin decreases connective tissue growth factor to improve liver fibrosis in rats treated with carbon tetrachloride. Phytotherapy Research Ptr. 2013;27(7):1023-8.

14. Pientaweeratch S, Panapisal V, Tansirikongkol A. Antioxidant, anticollagenase and anti-elastase activities of Phyllanthus emblica, Manilkara zapota and silymarin: an in vitro comparative study for anti-aging applications. Pharm Biol. 2016;54(9):1865-72.

15. Keshk WA, Zahran SM, Katary MA, Ali DAEA. Modulatory effect of silymarin on nuclear factor-erythroid-2-related factor 2 regulated redox status, nuclear factor-KB mediated inflammation and apoptosis in experimental gastric ulcer. Chem Biol Interact. 2017;273:266.

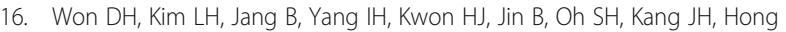
SD, Shin JA, et al. In vitro and in vivo anti-cancer activity of silymarin on oral cancer. Tumour Biol. 2018;40(5):1010428318776170.

17. Johannes D, Gabriele W, Mcgregor GP, Kurt A. Assessment of a dry extract from milk thistle (Silybum marianum) for interference with human liver cytochrome-P450 activities. Toxicology in Vitro An International Journal Published in Association with Bibra. 2011;25(1):21-7.

18. Reisinger N, Schaumberger S, Nagl V, Hessenberger S, Schatzmayr G. Milk thistle extract and Silymarin inhibit lipopolysaccharide induced lamellar separation of hoof explants in vitro. Toxins (Basel). 2014;6(10):2962-74.

19. Lee SB, Shim S, Kim MJ, Shin HY, Jang WS, Lee SJ, Jin YW, Lee SS, Park S. Identification of a distinct sub population of fibroblasts from murine dermis: CD73(-) CD105(+) as potential marker of dermal fibroblasts subset with multipotency. Cell Biol Int. 2016:40(9):1008.

20. Feng Y, Wang J, Ling S, Li Z, Li M, Li Q, Ma Z, Yu S. Differentiation of mesenchymal stem cells into neuronal cells on fetal bovine acellular dermal matrix as a tissue engineered nerve scaffold. Neural Regen Res. 2014;9(22):1968

21. Richter C, Viergutz T, Schwerin M, Weitzel JM. Prostaglandin E synthase interacts with inducible heat shock protein 70 after heat stress in bovine primary dermal fibroblast cells. Cytometry Part A. 2015;87(1):61-7.
22. Benjamin AL, Green BB, Crooker BA, Mckay SD, Kerr DE. Differential responsiveness of Holstein and Angus dermal fibroblasts to LPS challenge occurs without major differences in the methylome. BMC Genomics. 2016; 17(1):258.

23. Hendry KAK, Lancelott MJ, Knight CH, Kempson SA, Wilde CJ. Protein synthesis in tissues cultured from the bovine hoof. Cell Tissue Res. 1995: 281(1):93-9.

24. West AP, Koblansky AA, Ghosh S. Recognition and signaling by toll-like receptors. Annu Rev Cell Dev Biol. 2006;22(1):409-37.

25. Ansari N, Khodagholi F, Amini M, Shaerzadeh F. Attenuation of LPS-induced apoptosis in NGF-differentiated PC12 cells via NF-kappaB pathway and regulation of cellular redox status by an oxazine derivative. Biochimie. 2011; 93(5):899-908.

26. Karin M. NF-KB at the crossroads of life and death. Nat Immunol. 2002;3(3):221-7.

27. Camacho-Barquero L, Villegas I, Sánchez-Calvo JM, Talero E, Sánchez-Fidalgo S, Motilva V, Lastra CADL. Curcumin, a Curcuma longa constituent, acts on MAPK p38 pathway modulating COX-2 and iNOS expression in chronic experimental colitis. Int Immunopharmacol. 2007;7(3):333-42.

28. Won M, Byun HS, Park KA, Gang MH. Post-translational control of NF-KB signaling by ubiquitination. Arch Pharm Res. 2016;39(8):1075-84.

29. Ayroldi E, Cannarile L, Migliorati G, Nocentini G, Delfino DV, Riccardi C. Mechanisms of the anti-inflammatory effects of glucocorticoids: genomic and nongenomic interference with MAPK signaling pathways. FASEB J. 2012;26(12):4805-20.

30. Kwon S, Moore JN, Robertson TP, Hurley DJ, Wagner B, Vandenplas ML. Disparate effects of LPS infusion and carbohydrate overload on inflammatory gene expression in equine laminae. Vet Immunol Immunopathol. 2013;155(1-2):1-8.

31. Waguespack RW, Kemppainen RJ, Cochran A, Lin HC, Belknap JK. Increased expression of MAlL, a cytokine-associated nuclear protein, in the prodromal stage of black walnut-induced laminitis. Equine Vet J. 2010;36(3):285-91.

32. Hiratsuka M. In vitro assessment of the allelic variants of cytochrome P450. Drug Metab Pharmacokinet. 2012;27(1):68-84

33. Nebert DW, Russell DW. Clinical importance of the cytochromes P450. Lancet. 2002;360(9340):1155-62.

34. Morgan ET. Regulation of cytochromes P450 during inflammation and infection. Drug Metab Rev. 1997;29(4):1129-88.

35. Dickmann LJ, Patel SK, Wienkers LC, J Greg S. Effects of interleukin $1 \beta$ (IL-1 $\beta$ ) and IL-1 $\beta$ /interleukin 6 (IL-6) combinations on drug metabolizing enzymes in human hepatocyte culture. Curr Drug Metab. 2012;13(7).

36. Yang $\mathrm{KH}$, Lee MG. Effects of endotoxin derived from Escherichia coli lipopolysaccharide on the pharmacokinetics of drugs. Arch Pharm Res. 2008; 31(9):1073-86.

37. Kato $R$, Yamashita $S$, Moriguchi J, Nakagawa M, Tsukura $Y$, Uchida $K$, Amano F, Hirotani $Y$, ljiri Y, Tanaka K. Changes of midazolam pharmacokinetics in Wistar rats treated with lipopolysaccharide: relationship between total CYP and CYP3A2. Innate Immun. 2008;14(5):291-7.

38. Bran JA, Daros RR, Keyserlingk MAGV, Hötzel MJ. Lameness on Brazilian pasture based dairies-part 1: farmers' awareness and actions. Prev Vet Med. 2018.

39. Diandian L, Dan X, Tao W, Yongchun S, Shujin G, Xue Z, Lingli G, Xiaoou L, Lian L, Fuqiang W. Silymarin attenuates airway inflammation induced by cigarette smoke in mice. Inflammation. 2015;38(2):871-8.

40. Kamal RA, Mehdi AO, Reza S, Pezhman B, Mehdi HN, Nahid A, MohammadReza S. Silymarin alleviates bleomycin-induced pulmonary toxicity and lipid peroxidation in mice. Pharm Biol. 2014;52(10):1267-71.

41. Abdel-Moneim AM, Al-Kahtani MA, El-Kersh MA, Al-Omair MA. Free radicalscavenging, anti-inflammatory/anti-fibrotic and Hepatoprotective actions of taurine and Silymarin against CCI4Induced rat liver damage. PLoS One. 2015;10(12):e0144509.

42. Kim EJ, Lee MY, Jeon YJ. Silymarin inhibits morphological changes in LPSstimulated macrophages by blocking NF-kB pathway. Korean Journal of Physiology \& Pharmacology Official Journal of the Korean Physiological Society \& the Korean Society of Pharmacology. 2015;19(3):211.

43. Christmas P. Role of cytochrome P450s in inflammation. Adv Pharmacol. 2015:74:163-92. 